\title{
Obstacles to cadaver use for the development of neurosurgical techniques and devices in Japan
}

\author{
Yoshio Araki $^{1} \mathbb{0} \cdot$ Toshiaki Shichinohe $^{2} \cdot$ Takane Suzuki $^{3} \cdot$ Eiji Kobayashi $^{4}$
}

Received: 18 September 2021 / Revised: 13 January 2022 / Accepted: 27 February 2022 / Published online: 4 March 2022

(c) The Author(s), under exclusive licence to Springer-Verlag GmbH Germany, part of Springer Nature 2022

In recent years, with the development of new neurosurgical techniques and devices, increasingly advanced knowledge and techniques are needed to safely perform surgeries. Medical accidents caused by surgeons performing procedures without sufficient experience have become a substantial challenge to society. Surgical training has always focused on learning in the operating room under the supervision of a senior surgeon. However, it is difficult to learn complicated anatomical structures and surgical approaches only by learning from the actual surgery. Therefore, there is an urgent need to build an educational programme for trainees with minimal risk to patients.

We are very interested in the recent review article by Iwanaga et al. [5]. These authors analysed 37 cadaveric anatomical feasibility studies and investigated the required for the work to be clinically applied and published. The analysis showed that approximately $22 \%$ of the studies were clinically applied in the field of neurosurgery within 7 years after publication, and the median time until citation was 3.4 years [5]. In contrast, it has been reported that the time required for conventional clinical translational research to be applied clinically is 17 years [15]. Given that cadaveric anatomical studies are approximately 2.5 times faster than clinical translational research from the start of research to the treatment

Yoshio Araki

y.araki@med.nagoya-u.ac.jp

1 Department of Neurosurgery, Nagoya University Graduate School of Medicine, 65 Tsurumai-cho, Showa-ku, Nagoya, Aichi, Japan

2 Department of Gastroenterological Surgery II, Hokkaido University Faculty of Medicine, Kita 15-jo Nishi 7-chome, Kita-ku, Sapporo, Japan

3 Department of Bioenvironmental Medicine, Graduate School of Medicine, Chiba University, 1-8-1 Inohana, Chuo-ku, Chiba, Japan

4 Department of Kidney Regenerative Medicine, Jikei University School of Medicine, 3-25-8 Nishi-Shimbashi, Minato-ku, Tokyo, Japan of patients, cadaveric research could be a potential strategy for advancing the field of neurosurgery. We applaud the work by Iwanaga et al. and thank these authors for providing valuable information.

The importance and necessity of the cadaver laboratory in the education of neurosurgeons have been widely recognized internationally. Recently, even in developing countries, neurosurgical cadaver laboratories have begun to be established with limited medical resources [18, 19]. In addition to surgical training, new surgical approach development by cadaveric research has been carried out in cadaver laboratories [20,21]. On the other hand, there is not a large number of cadavers available in each country [2,3]. Recently developed three-dimensional (3D) print models may be promising solutions to the global shortage of cadavers [13]. In particular, disease-specific models such as those with cerebral aneurysms and brain tumours are becoming more accurate and are promising methods for preoperative simulation from a realistic perspective $[1,10,11,22]$. However, due to the difficult construction of materials, some prototypes lacked brain tissue, and some used animal brain tissue [4, 23]. The 3D model has not been sufficiently verified for its usefulness in comparison with the educational tools such as two-dimensional models developed for residents. In addition, multifaceted evaluations such as anatomical accuracy, usefulness as a surgical training model, and cost for new 3D models should be continued, and comparison with CST should be performed.

In Japan, the Japan Surgical Society (JSS) cooperated with the Japanese Association of Anatomists (JAA) and drafted the "Guidelines for Cadaver Dissection in Education and Research of Clinical Medicine" in 2012. With the establishment of a special committee by the JSS, all universities hosting cadaver surgical training (CST) are obligated to report the content of their CST implementation and their budgetary investment each year, considering the ethical importance of CST. Since this guideline was implemented, programmes for CST and organizations conducting cadaver 
surgical research have gradually increased; approximately $40 \%$ of medical universities conduct such activities $[8,17]$. The field of neurosurgery accounts for approximately $10 \%$ of all CST activity (28/261 in the 2021 report). In this field, training in clinical surgical techniques using experimental animals, such as pigs, and artificial materials composed of biomaterials is not anatomically feasible.

However, we are concerned that research and development (R\&D) using cadavers is extremely scarce in Japan compared to other countries. Over the past 10 years, there have been 797 CST and cadaver-based R\&D reports, and only 10 of these reports involved the use of cadavers for medical device R\&D [17]. Efforts in this field in Japan have been delayed compared to other countries. Following CST, the spread of R\&D with cadavers must be made an urgent priority in Japan [17]. If this situation does not improve, the development of "made-in-Japan" medical devices will be further delayed. Not only the JSS and JAA. However, also other related societies should share this concern.

The COVID-19 pandemic has had a serious impact on the provision of medical resources worldwide. According to a questionnaire survey of 34 neurosurgical centres in 26 countries, $80 \%$ of the facilities that responded were significantly restricted in their activities compared to before the pandemic [12]. Of further concern is the difficulty of conducting CST and cadaveric R\&D due to the serious effects of COVID19 [9]. The length of time the active virus remains in the body after death, especially in the nasal cavity and trachea, has not been clarified. The risk of coronavirus infection in those who handle cadaver bodies has not been confirmed to be eliminated by the Thiel embalming method, which is the main method used in Japan and Europe [14]. In addition, it has been speculated that densely implemented CST tends to be avoided from the viewpoint of infection prevention. As a result, the number of cadavers provided by each university for CST has decreased in Japan from 256 reports in fiscal year (FY) 2019 (2019 Mar.-2020 Apr.) to 126 in FY2020. Few reports regarding the risk management of coronavirus infection in neurosurgical procedures have been published. Kim et al. examined particle aerosolization in endoscopic skull base surgery in a cadaveric study and reported that negative pressure facial antechamber effectively reduced scattering [7]. In the field of otolaryngological surgery, whose procedures are similar to those of neurosurgery, the risk of exposure to coronavirus due to droplet and aerosol contamination has been verified in cadaveric research [16]. However, during the COVID-19 pandemic, CST performed using personal protective equipment in a facility with sufficient infection control is promising as an educational method.

In addition, Japanese medical device manufacturers have previously conducted cadaveric verification tests of prototypes in medical device R\&D at specialized facilities overseas. Due to the travel restrictions associated with the pandemic, these international activities have become difficult to implement. This situation clearly highlights the need to build an R\&D platform in Japan [17].

The effectiveness of CST in the education of neurosurgical anatomy, which has been cultivated for many years, is significantly impaired by the COVID-19 pandemic, and new educational methodologies have begun to be sought [6]. However, the rapid benefits of CST and cadaveric research may shed light on the neurosurgical practices hampered by the pandemic. Surprisingly, 10 cadaveric R\&Ds were reported last year, including new domestic robotic equipment for urology and gastrointestinal surgery. Such research could help drive the continuation and development of CST and cadaveric research during the COVID-19 pandemic [5].

Acknowledgements We thank all members of the CST Promotion Committee of the JSS, and we are also grateful to Mr. Kentaro Kaneko (Japan Surgery Society Secretariat) for contributing to the management of the CST data over the years.

Author contribution Inspection and approval of the final manuscript: all authors. Conception and design: YA and EK. Data acquisition: YA, EK, TS, and TS. Drafting of the article: YA and EK. Critical revision and advice: TS and TS. Supervision: EK.

Data availability The data and materials that support the findings of this study are available from the corresponding author upon reasonable request.

Code availability Not applicable.

\section{Declarations}

Ethics approval Not applicable.

Consent to participate Not applicable.

Consent for publication Not applicable.

Conflict of interest The authors declare no competing interests.

\section{References}

1. Carlos GF, Enrrique FS, Aylen Andrea TG et al (2021) Introducing a realistic, low-cost simulation model for clipping of brain aneurysms. World Neurosurg. https://doi.org/10.1016/j.wneu. 2021.11.012

2. Chen D, Zhang Q, Deng J, Cai Y, Huang J, Li F, Xiong K (2018) A shortage of cadavers: the predicament of regional anatomy education in mainland China. Anat Sci Educ 11:397-402. https://doi. org/10.1002/ase. 1788

3. Ghosh SK (2017) Cadaveric dissection as an educational tool for anatomical sciences in the 21st century. Anat Sci Educ 10:286299. https://doi.org/10.1002/ase.1649

4. Grosch AS, Schröder T, Schröder T, Onken J, Picht T (2020) Development and initial evaluation of a novel simulation model 
for comprehensive brain surgery training. Acta Neurochir (Wien) 162:1957-1965. https://doi.org/10.1007/s00701-020-04359-w

5. Iwanaga J, Boggio NA, Bui CJ, Dumont AS, Tubbs RS (2021) Can anatomical feasibility studies drive neurosurgical procedures and reach patients faster than traditional translational research? Neurosurg Rev. https://doi.org/10.1007/s10143-021-01626-x

6. Iwanaga J, Loukas M, Dumont AS, Tubbs RS (2021) A review of anatomy education during and after the COVID-19 pandemic: revisiting traditional and modern methods to achieve future innovation. Clin Anat 34:108-114. https://doi.org/10.1002/ca.23655

7. Kim M, Lee M, Schwarz J, Kacker A, Schwartz TH (2021) A novel negative pressure, face-mounted antechamber to minimize aerosolization of particles during endoscopic skull base surgery. Oper Neurosurg (Hagerstown) 21:131-136. https://doi.org/10. 1093/ons/opab173

8. Kobayashi E, Nudeshima J (2018) Current state of surgical training using cadavers in Japan compared with Western countries. Surg Today 48:891-893. https://doi.org/10.1007/ s00595-018-1673-4

9. Kobayashi E, Shichinohe T, Suzuki T (2021) Cadaver surgical education and research under the SARS-CoV-2 pandemic in Japan. Otolaryngol Head Neck Surg. https://doi.org/10.1177/ 01945998211036422

10. Lan Q, Chen A, Zhang T et al (2016) Development of threedimensional printed craniocerebral models for simulated neurosurgery. World Neurosurg 91:434-442. https://doi.org/10.1016/j. wneu.2016.04.069

11. Mashiko T, Kaneko N, Konno T, Otani K, Nagayama R, Watanabe E (2017) Training in cerebral aneurysm clipping using self-made 3-dimensional models. J Surg Educ 74:681-689. https://doi.org/ 10.1016/j.jsurg.2016.12.010

12. Mathiesen T, Arraez M, Asser T et al (2020) A snapshot of European neurosurgery December 2019 vs. March 2020: just before and during the COVID-19 pandemic. Acta Neurochir (Wien) 162:2221-2233. https://doi.org/10.1007/s00701-020-04482-8

13. McGuire LS, Fuentes A, Alaraj A (2021) Three-dimensional in training, simulation, and surgical planning in open vascular and endovascular neurosurgery: a systematic review of the literature. World Neurosurg 154:53-63. https://doi.org/10.1016/j.wneu.2021. 07.057

14. Miyake S, Suenaga J, Miyazaki R et al (2020) Thiel's embalming method with additional intra-cerebral ventricular formalin injection (TEIF) for cadaver training of head and brain surgery. Anat Sci Int 95:564-570. https://doi.org/10.1007/s12565-020-00545-Z

15. Morris ZS, Wooding S, Grant J (2011) The answer is 17 years, what is the question: understanding time lags in translational research. J R Soc Med 104:510-520. https://doi.org/10.1258/jrsm. 2011.110180

16. Sharma D, Rubel KE, Ye MJ et al (2020) Cadaveric simulation of otologic procedures: an analysis of droplet splatter patterns during the COVID-19 pandemic. Otolaryngol Head Neck Surg 163:320-324. https://doi.org/10.1177/0194599820930245

17. Shichinohe T, Kobayashi E (2022) Cadaver surgical training in Japan: its past, present, and ideal future perspectives. Surg Today 52:354-358. https://doi.org/10.1007/s00595-021-02330-5

18. Signorelli F, Olivi A, De Giorgio F, Pascali VL, Visocchi M (2020) A $360^{\circ}$ Approach to the craniovertebral junction in a cadaveric laboratory setting: historical insights, current, and future perspectives in a comparative study. World Neurosurg 140:564-573. https://doi.org/10.1016/j.wneu.2020.04.058

19. Signorelli F, Stumpo V, Della Pepa GM, La Rocca G, Oliva A, Olivi A, Visocchi M (2019) Step-up establishment of neurosurgical laboratory starting with limited resources-tips and tricks. World Neurosurg 126:83-89. https://doi.org/10.1016/j.wneu.2019. 02.034

20. Visocchi M, La Rocca G, Della Pepa GM, Stigliano E, Costantini A, Di Nardo F, Maira G (2014) Anterior video-assisted approach to the craniovertebral junction: transnasal or transoral? A cadaver study. Acta Neurochir (Wien) 156:285-292. https://doi.org/10. 1007/s00701-013-1910-y

21. Visocchi M, Pappalardo G, Pileggi M, Signorelli F, Paludetti G, La Rocca G (2016) Experimental endoscopic angular domains of transnasal and transoral routes to the craniovertebral junction: light and shade. Spine Phila Pa 1976 41:669-677. https://doi.org/ 10.1097/brs.0000000000001288

22. Watanabe N, Yamamoto Y, Fujimura S et al (2021) Utility of multi-material three-dimensional print model in preoperative simulation for glioma surgery. J Clin Neurosci 93:200-205. https:// doi.org/10.1016/j.jocn.2021.09.017

23. Zhu J, Wen G, Tang C, Zhong C, Yang J, Ma C (2020) A practical 3d-printed model for training of endoscopic and exoscopic intracerebral surgery with a tubular retractor. J Neurol Surg A Cent Eur Neurosurg 81:404-411. https://doi.org/10.1055/s-0039-1697023

Publisher's note Springer Nature remains neutral with regard to jurisdictional claims in published maps and institutional affiliations. 